\title{
Exenatide once weekly treatment maintained improvements in glycemic control and weight loss over 2 years
}

Kristin Taylor ${ }^{1}$, Kate Gurney ${ }^{1 *}$, Jenny Han ${ }^{1}$, Richard Pencek ${ }^{1}$, Brandon Walsh ${ }^{1}$ and Michael Trautmann²

\begin{abstract}
Background: The once-weekly (QW) formulation of the glucagon-like peptide-1 receptor agonist exenatide has been demonstrated to improve A1C, fasting plasma glucose (FPG), body weight, serum lipid profiles, and blood pressure in patients with type 2 diabetes through 52 weeks of treatment. In this report, we describe the 2-year results of the open-label, open-ended extension to the DURATION-1 trial of exenatide QW for type 2 diabetes.

Methods: A 2-stage protocol was used: patients received either exenatide QW (2 mg) or exenatide twice daily for 30 weeks ( $5 \mu \mathrm{g}$ for the first 4 weeks and $10 \mu \mathrm{g}$ thereafter), followed by 1.5 years of treatment with exenatide QW ( $2 \mathrm{mg}$ ), for a total of 2 years (104 weeks) of exenatide treatment. Of the 295 (intent-to-treat [ITT) patients who entered the trial, $73 \%(n=216)$ completed 2 years of treatment (completer population). Baseline characteristics (mean \pm SE) for these patients were: A1C, $8.2 \pm$ 0.1\%; FPG, $168.4 \pm 43.0 \mathrm{mg} / \mathrm{dL}$; body weight, $101.1 \pm 18.7 \mathrm{~kg}$; and diabetes duration, $7 \pm 5$ years.

Results: In the completer population, significant improvements (LS mean $\pm \mathrm{SE}[95 \% \mathrm{CI}$ ) were maintained after 2 years of treatment in A1C (-1.71 $\pm 0.08 \%$ [-1.86 to $-1.55 \%])$, FPG $(-40.1 \pm 2.9 \mathrm{mg} / \mathrm{dL}[-45.7$ to $-34.5 \mathrm{mg} / \mathrm{dL}])$, and body weight $(-2.61 \pm 0.52 \mathrm{~kg}[-3.64$ to $-1.58 \mathrm{~kg}])$ compared with baseline. The percentages of patients who achieved an $\mathrm{A} 1 \mathrm{C}$ of $<7.0 \%$ and $\leq 6.5 \%$ at 2 years were $60 \%$ and $39 \%$, respectively. A significant reduction in systolic blood pressure (SBP; $-3.0 \pm 1.0 \mathrm{mmHg}[-4.9$ to $-1.1 \mathrm{mmHg}]$ ) was maintained through 2 years of treatment. Serum lipid profiles were also significantly improved, including triglycerides (geometric LS mean change from baseline, $-15 \pm 2.7 \%[-21 \%$ to $-10 \%])$, total cholesterol $(-8.6 \pm 2.8 \mathrm{mg} / \mathrm{dL}[-14.0$ to $-3.1 \mathrm{mg} / \mathrm{dL}])$, and low-density lipoproteins $(-4.5 \pm 2.2 \mathrm{mg} / \mathrm{dL}$ [-8.9 to $-0.01 \mathrm{mg} / \mathrm{dL}])$. Changes in A1C, body weight, FPG, SBP, and lipids in the ITT population were similar to those seen in the completer population. Nausea (predominantly mild in intensity) was the most common adverse event, although the frequency and intensity of nausea decreased over time. No severe hypoglycemia was observed.
\end{abstract}

Conclusions: Exenatide QW was well tolerated during the 2-year treatment period. This study demonstrated sustained glucose control and weight loss throughout 2 years of treatment with exenatide QW.

Trial Registration: ClinicalTrials.gov NCT00308139

\footnotetext{
* Correspondence: kate.gurney@amylin.com

${ }^{1}$ Amylin Pharmaceuticals, Inc., 9360 Towne Centre Drive, San Diego, CA

92121, USA

Full list of author information is available at the end of the article
} 


\section{Background}

Type 2 diabetes is characterized by progressive insulin resistance and pancreatic beta-cell dysfunction resulting in key defects in insulin secretion and function [1]. Ultimately, this leads to difficulties in controlling hyperglycemia, which has been associated with microvascular and macrovascular complications [2,3]. Because lowering of $\mathrm{A} 1 \mathrm{C}$ has been shown to reduce the risk of long-term microvascular - and possibly macrovascular - complications [3-7], a target A1C level of $<7 \%$ has been recommended by the American Diabetes Association (ADA) [8] for patients with diabetes; the American Association of Clinical Endocrinologists and the American College of Endocrinology (AACE/ ACE) [9] have recommended a more stringent A1C target of $\leq 6.5 \%$. Thus, the overall goal for the treatment of type 2 diabetes is to reduce $\mathrm{A} 1 \mathrm{C}$ to as near normal levels as possible, with considerations for the risk of hypoglycemia and the risk of comorbidites that are common in type 2 diabetes, including obesity, dyslipidemia, and hypertension.

Treatment of type 2 diabetes often begins with lifestyle modifications, but as the disease progresses, most patients require pharmacotherapy. However, many patients with type 2 diabetes do not maintain the recommended glycemic targets over time with traditional therapies and must transition to combination therapy and/or increasing doses of insulin as their glycemic control deteriorates $[5,6,10,11]$. Furthermore, the use of many antihyperglycemic agents can be accompanied by increased hypoglycemia, weight gain, and a persistence of elevated postprandial glucose excursions [3]. To address the need for more comprehensive treatment of type 2 diabetes, recent algorithms developed by the AACE and ADA/European Association for the Study of Diabetes have recommended the use of glucagon-like peptide-1 (GLP-1) receptor agonists (monotherapy or combination therapy) on the basis of their effective glycemic control, weight loss effects, low rates of hypoglycemia, and overall safety profiles, and particularly for use in patients for whom hypoglycemia is especially undesirable or promotion of weight loss is a major consideration $[2,9,11]$.

Exenatide is a potent GLP-1 receptor agonist with multiple glucoregulatory effects for the treatment of type 2 diabetes [12-18]. Treatment with exenatide twice daily (BID) enhances glucose-dependent insulin secretion, reduces inappropriate elevations in glucagon secretion, slows gastric emptying, and reduces body weight in a substantial proportion of treated patients [13-19]. Furthermore, the clinical effects of exenatide are sustained over time, as shown in long-term studies of exenatide BID $[19,20]$.
The sustained-release formulation of exenatide, exenatide once-weekly $(\mathrm{QW})$, allows for continuous drug release over time, resulting in sustained therapeutic levels of exenatide - and thus, 24-hour glycemic control - with a single weekly injection [21,22]. Providing continuous GLP-1 receptor agonism has emerged as an increasingly important opportunity in treating type 2 diabetes, as evidence indicates that controlling both fasting and postprandial hyperglycemia is essential to providing comprehensive glycemic control [23,24].

The DURATION-1 trial was designed to compare the safety and efficacy of exenatide BID with exenatide QW in patients with type 2 diabetes. This 2-stage protocol consisted of a randomized, open-label comparison of exenatide QW and exenatide BID for 30 weeks, followed by an open-ended assessment period in which all patients received exenatide QW. The results from the 30 - and 52-week assessment periods have previously been reported $[25,26]$. The objective of this report is to describe the safety and efficacy of 2 years of exenatide QW treatment in patients with type 2 diabetes.

\section{Methods}

\section{Randomization and interventions}

Patients were randomized to one of two open-label treatment groups: 1) weekly subcutaneous (SC) injections of $2 \mathrm{mg}$ exenatide QW or 2) SC injections of exenatide 5 $\mu \mathrm{g}$ BID for the first 4 weeks followed by a dose increase to $10 \mu \mathrm{g}$ BID for the remainder of the 30 -week assessment period. The inclusion and exclusion criteria have previously been reported [25]. At 30 weeks, participants entered an open-ended treatment period in which all patients received exenatide QW. Patients who were originally randomized to exenatide BID were switched to exenatide QW, and those originally randomized to exenatide QW continued their treatment regimens. Patients who were switched to exenatide QW at week 30 and who were concomitantly using a sulfonylurea (SFU) were required to reduce the SFU dose to the minimum recommended dose until week 40 . Subsequently, the SFU dose was titrated up based on daily glucose measurements to a target fasting plasma glucose (FPG) of $\leq 110 \mathrm{mg} / \mathrm{dL}$.

A common clinical protocol was approved for each study site by the appropriate Institutional Review Board. Patients provided written informed consent prior to participation. The study was conducted in accordance with the principles described in the Declaration of Helsinki, including all amendments through the South Africa revision of 1996 [27].

\section{Outcomes}

The objectives of this study were to examine the effects of exenatide QW on glycemic control, body weight, 
fasting lipids, and blood pressure after 2 years of treatment. Efficacy, safety, and tolerability were assessed in all patients, including intent-to-treat (ITT) and completer populations. Plasma analytes and $\mathrm{A} 1 \mathrm{C}$ were quantitated by Quintiles Laboratories (Smyrna, GA) using standard methods [25].

\section{Statistical analysis}

All randomized patients who received at least one injection of exenatide in the 30-week phase of this study were defined as the ITT population. The 2-year (104-week) completer population consisted of patients from the ITT population who completed the study procedures through week 100 in compliance with the protocol and who received at least 96 weeks of treatment. At week 52, there were no significant differences in change from baseline $\mathrm{A} 1 \mathrm{C}$ or the percentage of patients who achieved target $\mathrm{A} 1 \mathrm{C}$ between the group initially randomized to exenatide QW and the group initially randomized to exenatide BID (who switched to exenatide QW at week 30) [26]. Thus, in this 2-year assessment, the completer population consisted of all patients regardless of initial randomization. Descriptive statistics on demographics and analyses of primary glycemic endpoints, body weight, blood pressure, and fasting lipid concentrations are provided for both the completer and ITT populations. For ITT analyses, the last observation carried forward (LOCF) method was applied to include data collected from the early withdrawals. The analyses of $\mathrm{A} 1 \mathrm{C}$ were based on a general linear model (ANOVA) including original treatment assignment, baseline $\mathrm{A} 1 \mathrm{C}$ strata, and concomitant SFU use at screening as factors. Baseline FPG, body weight, and blood pressure were added in the model (ANCOVA) for each respective parameter. Efficacy endpoint results are expressed as least square (LS) means. Statistical analysis was performed using SAS (8.2; SAS Institute, Inc., North Carolina).

Treatment-emergent adverse events (TEAEs) were defined as events that occurred during or after the first injection of randomized treatment. Hypoglycemic episodes were classified as major (i.e., severe) if 1) the event resulted in loss of consciousness, seizure, coma, or other change in mental status consistent with neuroglycopenia (as judged by the investigator or physician), in which symptoms resolved after administration of intramuscular glucagon or intravenous glucose, or 2) the event required third-party assistance because of severe impairment in consciousness or behavior and was accompanied by a blood glucose concentration of $<54$ $\mathrm{mg} / \mathrm{dL}$ (3.0 mmol/L). Minor hypoglycemia was defined as a report of symptoms consistent with hypoglycemia and a glucose value of $<54 \mathrm{mg} / \mathrm{dL}$ prior to treatment of the episode. Safety analyses are provided for the ITT population.

\section{Results}

\section{Patient disposition and baseline characteristics}

Demographic characteristics of the completer population $(n=216)$ are described in Figure 1. Of the 295 patients included in the ITT population, $73 \%$ completed 2 years of treatment (Figure 1). The most common reason for study withdrawal was withdrawal of consent. The demographic characteristics of the ITT population (sex, 53\% male; mean age, 55 y; Caucasian, 78\%; Black, 10\%; Hispanic, 12\%; Asian, <1\%; mean weight, $102 \mathrm{~kg}$; body mass index, $35 \mathrm{~kg} / \mathrm{m}^{2}$; A1C, 8.3; FPG, $169 \mathrm{mg} / \mathrm{dL}$; duration of diabetes, 7 y) were nearly identical to the 2 -year completer population.

\section{Effects on glycemic control and body weight}

The results reported here for the completer population and ITT population consist of all patients regardless of initial randomization. Overall, patients in the 2-year completer population maintained improvements in A1C (Figure 2A), with LS mean \pm SE (95\% CI) change from baseline $\mathrm{A} 1 \mathrm{C}$ of $-1.7 \pm 0.08 \%$ ( -1.86 to $-1.55 \%)$. The mean change from baseline $\mathrm{A} 1 \mathrm{C}$ in the ITT population was $-1.5 \pm 0.07 \%$. At the end of the 2 -year assessment period, $60 \%$ of patients achieved A1C of $<7.0 \%, 39 \%$ achieved $\mathrm{A} 1 \mathrm{C}$ of $\leq 6.5 \%$, and $17 \%$ achieved normoglycemia (i.e., $\leq 6.0 \%$ ) (Figure 2B). The percentage of patients in the ITT population who achieved these glycemic goals were similar to those in the completer population and are shown Figure 2B. Overall, $89 \%$ of patients in the completer population achieved a reduction in $\mathrm{A} 1 \mathrm{C}$ at year 2 (Figure 3B). In patients who received 2 years of treatment, FPG decreased by $40.1 \pm 2.9 \mathrm{mg} / \mathrm{dL}(-45.7$ to $-34.5 \mathrm{mg} / \mathrm{dL}$ ) (Figure 2C).

Body weight reduction was generally maintained during the study; at the end of the 2-year assessment period, body weight (mean \pm SE $[95 \% \mathrm{CI}]$ ) was reduced by $2.6 \pm 0.5 \mathrm{~kg}(-3.64$ to $-1.58 \mathrm{~kg})$ in the completer population and $2.4 \pm 0.4 \mathrm{~kg}(-3.19$ to $-1.53 \mathrm{~kg})$ in the ITT population (Figure $3 \mathrm{~A}$ ). The distribution of the change in $\mathrm{A} 1 \mathrm{C}$ with respect to changes in body weight is shown in Figure 3B for the completer population. At 2 years of treatment, $66 \%$ of patients experienced weight loss and $61 \%$ achieved reductions in both A1C and body weight.

\section{Effects on blood pressure and fasting lipids}

Significant improvements in systolic blood pressure (SBP) were observed in patients treated with exenatide QW (Figure 3C): the mean change $\pm \mathrm{SE}(95 \% \mathrm{CI})$ from baseline was $-3.0 \pm 1.0 \mathrm{mmHg}(-4.9$ to $-1.1 \mathrm{mmHg})$ in the completer population and $-2.1 \pm 1.0 \mathrm{mmHg}(-3.8$ to -0.5 $\mathrm{mmHg}$ ) in the ITT population. Improvement in diastolic blood pressure (data not shown) was also significant in the completer population $(-1.5 \pm 1.0 \mathrm{mmHg}[-2.8$ to -0.2 $\mathrm{mmHg}])$, but not in the ITT population $(-0.8 \pm 0.6$ 


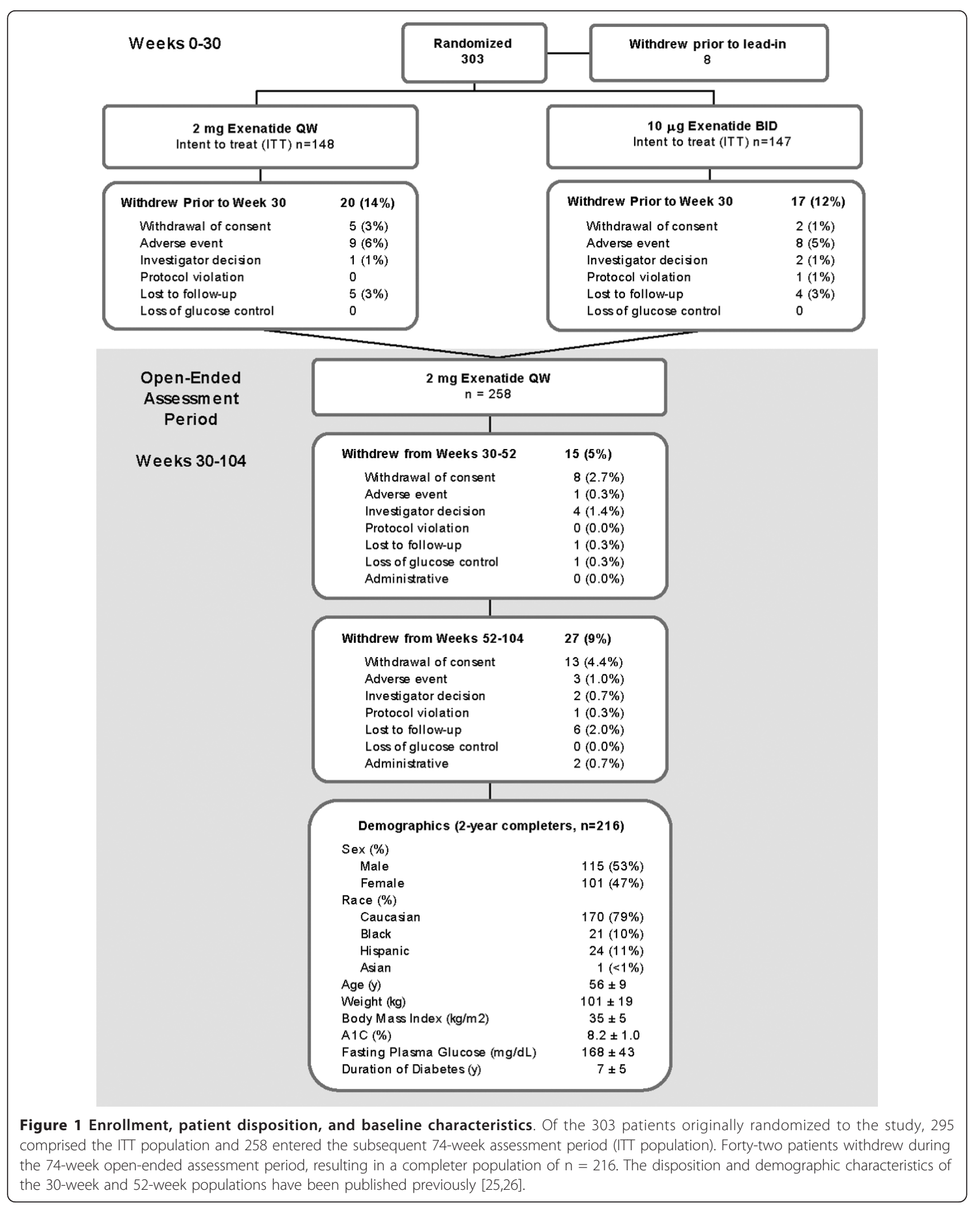



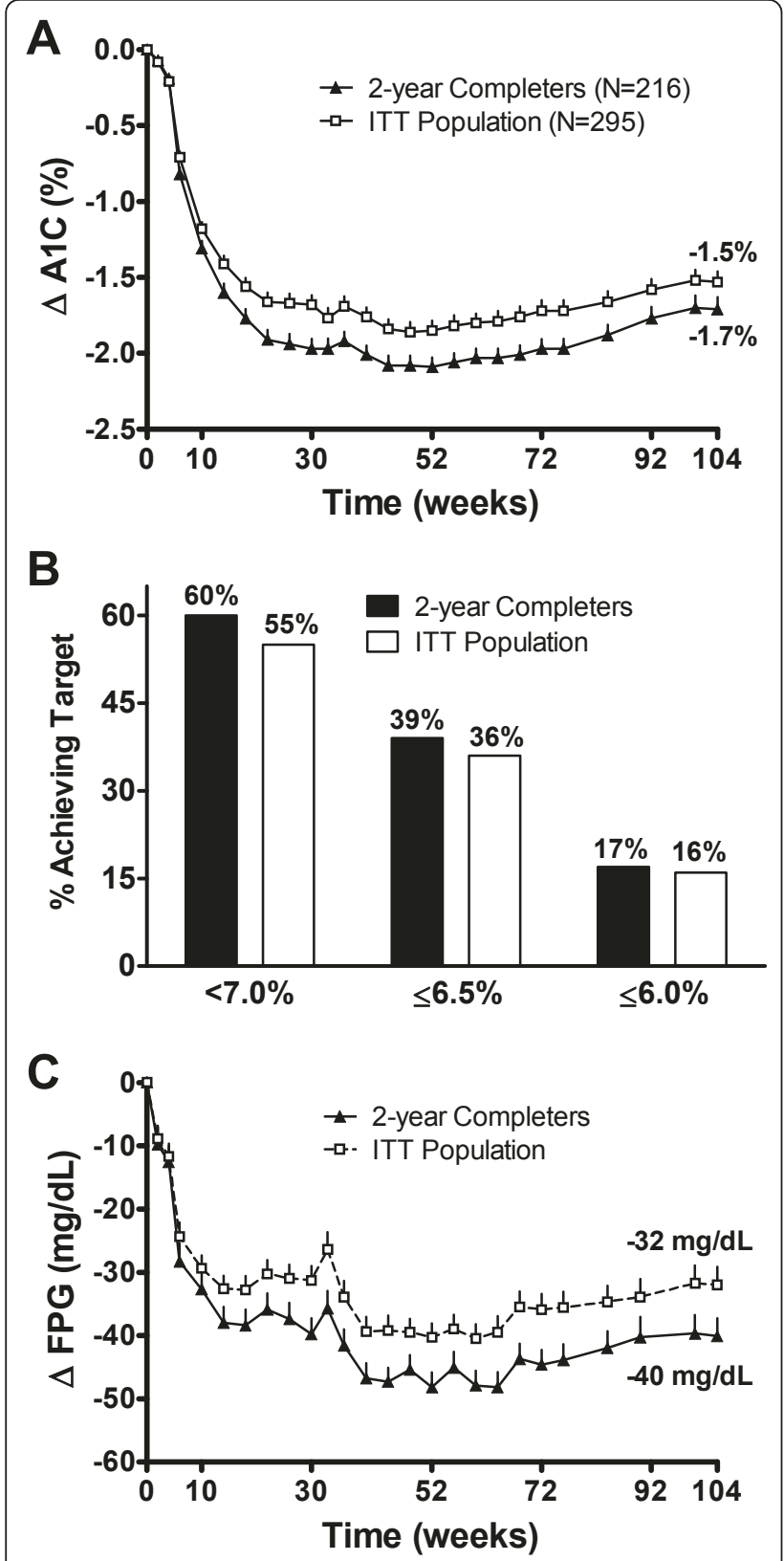

Figure 2 Improvements in glycemic control over 104 weeks in the completer population ( $\mathrm{N}=216)$ and intent-to-treat population $(\mathbf{N}=\mathbf{2 9 5})$. A) LS mean \pm SE changes in A1C over 104 weeks. Baseline (BL) was $8.2 \%$ in the 2-year completer population and $8.3 \%$ in the ITT population. B) Proportion of patients who achieved A1C targets of $<7.0 \%, \leq 6.5 \%$, and $\leq 6.0 \%$. C) LS mean \pm SE changes in fasting plasma glucose over 104 weeks. Baseline was $168 \mathrm{mg} / \mathrm{dL}$ in the 2-year completer population and $169 \mathrm{mg} / \mathrm{dL}$ in the ITT population.

mmHg [ -2.0 to $0.3 \mathrm{mmHg}]$ ). Improvements (LS mean change $[95 \% \mathrm{CI}]$ ) in serum lipid profiles were demonstrated after 2 years of treatment (completer population), with clinically significant reductions from baseline in total cholesterol $(-8.6 \pm 2.8 \mathrm{mg} / \mathrm{dL}[-14.0$ to $-3.1 \mathrm{mg} / \mathrm{dL}])$, low- density lipoproteins (LDL; $-4.5 \pm 2.2 \mathrm{mg} / \mathrm{dL}[-8.9$ to -0.01 $\mathrm{mg} / \mathrm{dL}]$ ), and triglycerides (geometric LS mean percent change \pm SE $-15 \pm 2.7 \%$ [-21\% to $-10 \%]$; Figure 3D). Similarly, changes in the ITT population were $-8.2 \pm 2.3$ $\mathrm{mg} / \mathrm{dL}(-12.7$ to $-3.7 \mathrm{mg} / \mathrm{dL})$ for total cholesterol, $-3.9 \pm$ $1.8 \mathrm{mg} / \mathrm{dL}(-7.5$ to $-0.3 \mathrm{mg} / \mathrm{dL})$ for $\mathrm{LDL}$, and $-12 \pm 2.7 \%$ $(-21 \%$ to $-10 \%)$ for triglycerides.

\section{Safety and tolerability}

Frequent ( $\geq 5 \%)$ TEAEs that occurred for the first time or worsened after receiving exenatide QW from weeks 0 to 30 and weeks 30 to 104 (ITT population) are described in Table 1. The adverse event (AE) profile for exenatide BID treatment from weeks 0 to 30 was previously reported [25]. Overall, the types of events reported with exenatide were similar for the controlled (weeks 0-30) and uncontrolled (weeks 30-104) portions of the trial, with no new tolerability or safety issues identified. Nausea was the most common AE throughout the trial and was predominantly mild in intensity; no severe nausea was reported. The proportion of patients who experienced nausea decreased during the second phase (weeks 30104) of the trial: the incidence of nausea during the initial 30 weeks of treatment was $27 \%$ in the exenatide QW group and 35\% in exenatide BID group, both of which decreased to $12 \%$, regardless of initial treatment, from week 30 to week 104. The incidence of injection site pruritis and injection site erythema also declined from week 30 (18\% and 7\%, respectively) to week 104 (4\% for both), and no injection-site-related AEs led to withdrawal during the uncontrolled period. There were no episodes of major hypoglycemia. Of the 17 patients who experienced a minor hypoglycemic event between weeks 30 and 104, 16 were using a concomitant SFU. From week 30 to week 104, only 4 patients withdrew because of an AE: nausea, cholestatic hepatitis, positive antibody test, diabetes mellitus, and breast cancer. The incidence of serious AEs was generally low (11\% at week 104) and there was no consistent pattern of reported events. Additionally, no cases of pancreatitis were reported.

\section{Discussion}

Guidelines for the treatment of type 2 diabetes are currently focused on the use of agents that provide effective lowering of $\mathrm{A} 1 \mathrm{C}$, have beneficial effects on extraglycemic factors associated with long-term complications, and have favorable safety and tolerability profiles $[9,28]$. Recently, GLP-1 receptor agonists have been recommended as a treatment option for patients in whom hypoglycemia or weight gain are major concerns $[9,11]$. In particular, weight loss in type 2 diabetes is associated with improved insulin action and enhanced glycemic control [29], and it may favorably affect other comorbidites associated with diabetes such as hypertension and dyslipidemia [30]. 


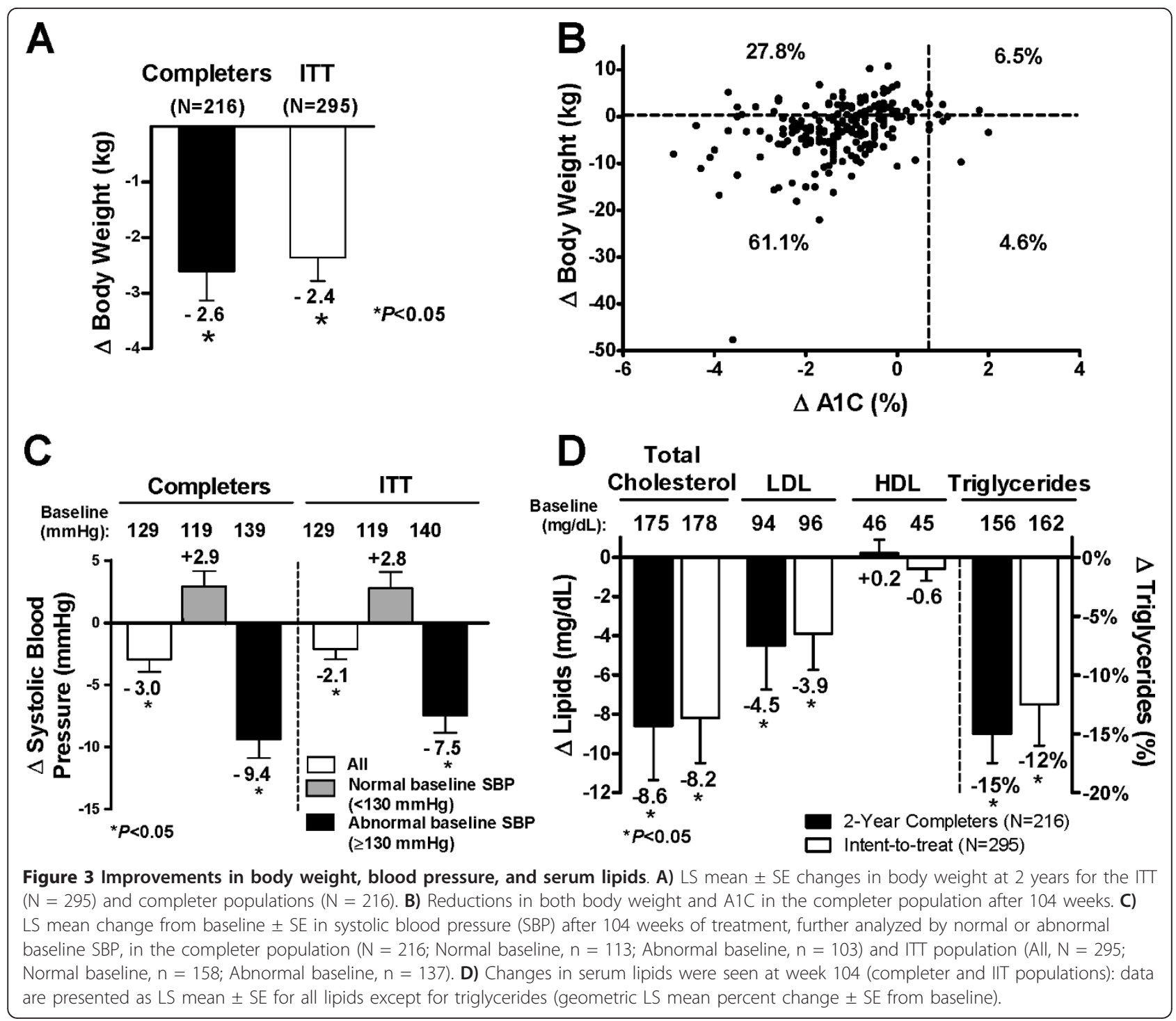

The improvements in glycemic control that were previously reported with 52 weeks of exenatide QW treatment [26] were sustained in the present study in patients continuing exenatide QW treatment for 2 years, regardless of the initial 30-week randomization of treatment (i.e., QW or BID). After 2 years of treatment, reductions in A1C remained durable in all patients (LS mean A1C change, $-1.7 \%)$. In addition to improvements in glycemic control, improvements were seen in several cardiovascular risk factors including body weight, blood pressure, and fasting lipids. Further studies are warranted to determine whether these improvements are associated with enhanced outcomes in patients with type 2 diabetes.

Exenatide once weekly vs. exenatide twice daily Previously reported results from this trial demonstrated that improvements in glycemic control achieved with exenatide QW were greater than those achieved with exenatide BID, with similar or greater improvements in other outcomes including body weight, blood pressure, and serum lipid profiles $[25,26]$. After 30 weeks of treatment, patients who received exenatide QW had a greater mean A1C reduction $(-1.9 \%$ vs. $-1.5 \%)$ than did patients who received exenatide BID, and more exenatide QW-treated patients achieved target A1C levels of $<7.0 \%$ (77\% vs. $61 \%$ ) [25]. Of note, patients who switched from exenatide BID to exenatide QW at week 30 exhibited further improvements in glycemic control such that at week 52, all patients, regardless of initial treatment, exhibited similar mean $\mathrm{A} 1 \mathrm{C}$ reductions $(-2.0 \%)$ [26]. In the present analysis, the observed mean $\mathrm{A} 1 \mathrm{C}$ reduction of $1.7 \%$ after 2 years of treatment suggests that glycemic control is maintained with exenatide QW, a finding that was also observed after 2 years of treatment with exenatide BID [20]. 
Table 1 Frequent ( $\geq 5 \%$ ) Treatment-emergent Adverse Events with Exenatide Once Weekly During Weeks 0 to 30 and Weeks 30 to 104

\begin{tabular}{|c|c|c|}
\hline Adverse Event & $\begin{array}{l}\text { Weeks } 0 \text { to } 30 \\
\left(n=148^{*}\right) \\
(\% \text { of patients) }\end{array}$ & $\begin{array}{c}\text { Weeks } 30 \text { to } 104 \\
\left(n=258^{+}\right) \\
\text {(\% of patients) }\end{array}$ \\
\hline Nausea & 27 & 12 \\
\hline Vomiting & 11 & 9 \\
\hline Diarrhea & 15 & 12 \\
\hline Constipation & 11 & 5 \\
\hline Dyspepsia & 7 & 3 \\
\hline Gastroesophageal reflux disease & 7 & 4 \\
\hline Injection site pruritus & 18 & 4 \\
\hline Injection site erythema & 7 & 4 \\
\hline Urinary tract infection & 10 & 9 \\
\hline Gastroenteritis viral & 9 & 7 \\
\hline Nasopharyngitis & 7 & 16 \\
\hline Upper respiratory tract infection & 8 & 24 \\
\hline Sinusitis & 5 & 12 \\
\hline Influenza & 1 & 5 \\
\hline Headache & 6 & 5 \\
\hline Fatigue & 6 & 4 \\
\hline Back pain & 5 & 7 \\
\hline Arthralgia & 5 & 6 \\
\hline Pain in extremity & 1 & 6 \\
\hline
\end{tabular}

*Patients randomized to exenatide QW.

${ }^{\dagger}$ Patients who continued exenatide QW or switched from exenatide BID to exenatide QW.

\section{GLP-1 receptor agonists and dipeptidyl} peptidase-4 (DDP-4) inhibitors

Other GLP-1-related therapies currently available for the treatment of type 2 diabetes are the once-daily GLP-1 receptor agonist, liraglutide, and the once-daily DPP-4 inhibitors sitagliptin and saxagliptin [31-33]. The GLP-1 receptor agonists (exenatide BID or QW and liraglutide) have been shown to be more efficacious at providing glycemic control and promoting weight loss than the DPP-4 inhibitors, although with more gastrointestinal side effects than with DPP-4 inhibitors $[31,34,35]$. A comparison study between exenatide BID and liraglutide showed that both therapies had significant effects on $\mathrm{A} 1 \mathrm{C}$, as determined by a noninferiority comparison [31]; however, reductions were significantly greater with liraglutide (mean A1C change, $-1.1 \%)$ than with exenatide BID (-0.8\%). Weight loss was similar between exenatide BID and liraglutide (approximately $3 \mathrm{~kg}$ ). At this time, the results of a comparison study of exenatide QW and liraglutide are not yet available (ClinicalTrials.gov Identifier NCT01029886).

\section{Safety and tolerability}

Treatment with exenatide QW was safe and well tolerated during the 2-year assessment period, with a retention rate of $73 \%$. Adverse events (AEs) were generally mild to moderate. Few patients who received exenatide QW withdrew due to an $\mathrm{AE}$ (1.4\% in the uncontrolled period) and there were no withdrawals from the study due to serious AEs. Mild nausea was common, but the frequency and severity of nausea decreased or abated over time. To date, no safety signals specific to exenatide QW have been identified in clinical trials.

\section{Study limitations}

There were several potential limitations of this study. The absence of a comparator arm during the 1.5-year uncontrolled period limits the conclusions that can be drawn from the results, and the open-label trial design inherently creates the potential for bias and can affect patient expectations. The trial design also complicates interpretation of the modest increases in A1C, FPG, and body weight seen from week 52 to week 104. Furthermore, the population was heterogeneous for background therapy with other antidiabetic drugs; however, the earlier results at 30 and 52 weeks in this study suggest that the data are consistent across populations, regardless of background therapy.

Results from both the ITT and completer populations were included in this study, and both populations present certain limitations to the interpretation of the results. For the ITT analysis, using a LOCF method is a conservative approach that accounts for early study withdrawal and provides a prediction of treatment effect for any subject who ever received treatment. The completer analysis mitigates the potentially large variations in treatment exposure by representing the actual efficacy for the full term of drug exposure. The results of the ITT analysis should, thus, be weighed against the results of the completer analysis, as efficacy data collected early in the trial (e.g., from subjects who withdrew early) may not be representative of the true treatment effect, which is established with increased duration of treatment exposure. However, subject retention is often a challenge in long-term trials and the results of the completer analysis may be affected by the composition of the completer population, which often includes a high proportion of subjects who experienced favorable outcomes with treatment and underrepresents subjects who had issues with tolerability or lack of efficacy.

\section{Conclusions}

The present analysis demonstrated durable efficacy with long-term exenatide QW therapy and showed that common AEs, especially nausea, subsided with time. The continuous release of exenatide in the once-weekly formulation produced continuous GLP-1 receptor activation leading to sustained control of both fasting and postprandial hyperglycemia, which resulted in enhanced 
improvements in A1C. Additionally, the convenience of the once-weekly injection of exenatide offers an attractive alternative to once- and twice-daily injections, and could improve treatment adherence in the clinical setting [36]. This combination of effects suggests that the use of exenatide QW may be a viable, long-term option for the treatment of patients with type 2 diabetes.

\section{Abbreviations}

AE: adverse event; BID: twice daily; BL: baseline; FPG: fasting plasma glucose; GLP-1: glucagon-like peptide-1; ITT: intent-to-treat; LOCF: last observation carried forward; LS: least squares; QW: once-weekly; SBP: systolic blood pressure; SC: subcutaneous; SD: standard deviation; SE: standard error; SFU: sulfonylurea.

\section{Acknowledgements}

The studies in this analysis were sponsored by Amylin Pharmaceuticals, Inc, San Diego, California, and Eli Lilly and Company, Indianapolis, Indiana. The authors thank the exenatide DURATION-1 (Diabetes Therapy Utilization: Researching Changes in A1C, Weight and Other Factors Through Intervention with Exenatide ONce Weekly) clinical team for their assistance in the conduct, reporting, and quality control of the studies; the DURATION1 study site investigators (Sherwyn Schwartz, Sam Miller, Richard Weinstein, Bethany Klopfenstein, Andrew Ahmann, Julio Rosenstock, John Pullman, Fred Whitehouse, G.M. Gollapudi, Douglas Schumacher, Mervyn Weerasinghe, Peter Weissman, Lyle Myers, Eric Klein, Thomas Littejohn, Thomas Moretto, Jon Shapiro, Daniel Lorber, Athena Philis-Tsimikas, David Kayne, Richard Bergenstal, Elizabeth Stevens, Danny Sugimoto, Bruce Berwald, Diane Krieger, Dean Kereiakes, Gary Lewis, Robert Henry, Mark Comianos, Munni Selagamsetty, Ronald Mayfield, John Buse and Daniel Drucker) and their staffs for conducting the study; the study patients for their participation; and Alkermes, Inc. for the development of and for manufacturing the long-acting release formulation of exenatide. Portions of these data were previously presented at the ADA 69 ${ }^{\text {th }}$ Scientific Sessions, New Orleans, Louisiana 2009.

\section{Author details}

${ }^{1}$ Amylin Pharmaceuticals, Inc., 9360 Towne Centre Drive, San Diego, CA 92121, USA. ㄹli Lilly and Company, Lilly Corporate Center: DC 6038, Indianapolis, IN 46285, USA.

\section{Authors' contributions}

$\mathrm{KT}, J \mathrm{H}$, and RP participated in the design of the analysis. JH and RP performed the statistical analysis. All authors were involved in the interpretation of the analysis. All authors were involved in drafting the manuscript or revising it critically for important intellectual content. All authors approved the final manuscript.

\section{Competing interests}

This study was funded by Amylin Pharmaceuticals, Inc. and Eli Lilly and Company. Dr. Gurney, Ms. Han, Dr. Pencek, and Dr. Walsh are employees of Amylin Pharmaceuticals, Inc. Dr. Taylor was previously an employee of Amylin Pharmaceuticals, Inc. Dr. Trautmann is an employee of Eli Lilly and Company. Amylin Pharmaceuticals, Inc. has a global agreement with Eli Lilly and Company to collaborate on the development and commercialization of exenatide. All authors own company stock and have stock options.

Received: 12 October 2010 Accepted: 29 April 2011

Published: 29 April 2011

\section{References}

1. Kahn SE: The relative contributions of insulin resistance and beta-cell dysfunction to the pathophysiology of Type 2 diabetes. Diabetologia 2003, 46(1):3-19.

2. Kendall DM, Cuddihy RM, Bergenstal RM: Clinical application of incretinbased therapy: therapeutic potential, patient selection and clinical use. Am J Med 2009, 122(6 Suppl):S37-S50.

3. Heine RJ, Van Gaal LF, Johns D, Mihm MJ, Widel MH, Brodows RG: Exenatide versus insulin glargine in patients with suboptimally controlled type 2 diabetes: a randomized trial. Ann Intern Med 2005, 143(8):559-569.

4. Matthews DR, Cull CA, Stratton IM, Holman RR, Turner RC: UKPDS 26: Sulphonylurea failure in non-insulin-dependent diabetic patients over six years. UK Prospective Diabetes Study (UKPDS) Group. Diabet Med 1998, 15(4):297-303.

5. United Kingdom Prospective Diabetes Study (UKPDS): 13: Relative efficacy of randomly allocated diet, sulphonylurea, insulin, or metformin in patients with newly diagnosed non-insulin dependent diabetes followed for three years. BMJ 1995, 310(6972):83-88.

6. UK Prospective Diabetes Study (UKPDS) Group (UPDSG): Intensive bloodglucose control with sulphonylureas or insulin compared with conventional treatment and risk of complications in patients with type 2 diabetes (UKPDS 33). Lancet 1998, 352(9131):837-853.

7. Greenfield S, Billimek J, Pellegrini F, Franciosi M, De Berardis G, Nicolucci A, Kaplan SH: Comorbidity affects the relationship between glycemic control and cardiovascular outcomes in diabetes: a cohort study. Ann Intern Med 2009, 151(12):854-860.

8. American Diabetes Association: Standards of medical care in diabetes. Diabetes Care 2004, 27(Suppl 1):S15-S35.

9. Rodbard HW, Jellinger PS, Davidson JA, Einhorn D, Garber AJ, Grunberger G, Handelsman Y, Horton ES, Lebovitz H, Levy P, et al: Statement by an American Association of Clinical Endocrinologists/American College of Endocrinology consensus panel on type 2 diabetes mellitus: an algorithm for glycemic control. Endocr Pract 2009, 15(6):540-559.

10. Turner RC, Cull CA, Frighi V, Holman RR: Glycemic control with diet, sulfonylurea, metformin, or insulin in patients with type 2 diabetes mellitus: progressive requirement for multiple therapies (UKPDS 49). UK Prospective Diabetes Study (UKPDS) Group. JAMA 1999, 281(21):2005-2012.

11. Nathan DM, Buse JB, Davidson MB, Ferrannini E, Holman RR, Sherwin R, Zinman B: Medical management of hyperglycemia in type 2 diabetes: a consensus algorithm for the initiation and adjustment of therapy: a consensus statement of the American Diabetes Association and the European Association for the Study of Diabetes. Diabetes Care 2009, 32(1):193-203.

12. Göke R, Fehmann HC, Linn T, Schmidt H, Krause M, Eng J, Göke B: Exendin4 is a high potency agonist and truncated exendin-(9-39)-amide an antagonist at the glucagon-like peptide 1-(7-36)-amide receptor of insulin-secreting $\beta$-cells. J Biol Chem 1993, 268(26):19650-19655.

13. Buse JB, Henry RR, Han J, Kim DD, Fineman MS, Baron AD, Exenatide-113 Clinical Study Group: Effects of exenatide (exendin-4) on glycemic control over 30 weeks in sulfonylurea-treated patients with type 2 diabetes. Diabetes Care 2004, 27(11):2628-2635.

14. Nielsen LL, Young AA, Parkes DG: Pharmacology of exenatide (synthetic exendin-4): a potential therapeutic for improved glycemic control of type 2 diabetes. Regul Pept 2004, 117(2):77-88.

15. DeFronzo RA, Ratner RE, Han J, Kim DD, Fineman MS, Baron AD: Effects of exenatide (exendin-4) on glycemic control and weight over 30 weeks in metformin-treated patients with type 2 diabetes. Diabetes Care 2005, 28(5):1092-1100.

16. Kendall DM, Riddle MC, Rosenstock J, Zhuang D, Kim DD, Fineman MS, Baron AD: Effects of exenatide (exendin-4) on glycemic control over 30 weeks in patients with type 2 diabetes treated with metformin and a sulfonylurea. Diabetes Care 2005, 28(5):1083-1091.

17. Zander M, Madsbad S, Madsen JL, Holst JJ: Effect of 6-week course of glucagon-like peptide 1 on glycaemic control, insulin sensitivity, and $\beta$ cell function in type 2 diabetes: a parallel-group study. Lancet 2002, 359(9309):824-830.

18. Zinman B, Hoogwerf BJ, Durán García S, Milton DR, Giaconia JM, Kim DD, Trautmann ME, Brodows RG: The effect of adding exenatide to a thiazolidinedione in suboptimally controlled type 2 diabetes: a randomized trial. Ann Intern Med 2007, 146(7):477-485.

19. Klonoff DC, Buse JB, Nielsen LL, Guan X, Bowlus CL, Holcombe JH, Wintle ME, Maggs DG: Exenatide effects on diabetes, obesity, cardiovascular risk factors and hepatic biomarkers in patients with type 2 diabetes treated for at least 3 years. Curr Med Res Opin 2008, 24(1):275-286.

20. Buse JB, Klonoff DC, Nielsen LL, Guan X, Bowlus CL, Holcombe JH, Maggs DG, Wintle ME: Metabolic effects of two years of exenatide treatment on diabetes, obesity, and hepatic biomarkers in patients with 
type 2 diabetes: an interim analysis of data from the open-label, uncontrolled extension of three double-blind, placebo-controlled trials. Clin Ther 2007, 29(1):139-153.

21. Kim D, MacConell L, Zhuang D, Kothare PA, Trautmann M, Fineman M, Taylor K: Effects of once-weekly dosing of a long-acting release formulation of exenatide on glucose control and body weight in subjects with type 2 diabetes. Diabetes Care 2007, 30(6):1487-1493.

22. Tracy MA, Ward KL, Firouzabadian L, Wang Y, Dong N, Qian R, Zhang Y: Factors affecting the degradation rate of poly(lactide-co-glycolide) microspheres in vivo and in vitro. Biomaterials 1999, 20(11):1057-1062.

23. Ceriello A: Postprandial hyperglycemia and diabetes complications: is it time to treat? Diabetes 2005, 54(1):1-7.

24. Monnier L, Lapinski $\mathrm{H}$, Colette $\mathrm{C}$ : Contributions of fasting and postprandial plasma glucose increments to the overall diurnal hyperglycemia of type 2 diabetic patients: variations with increasing levels of $\mathrm{HbA}(1 \mathrm{c})$. Diabetes Care 2003, 26(3):881-885.

25. Drucker DJ, Buse JB, Taylor K, Kendall DM, Trautmann M, Zhuang D, Porter L, DURATION-1 Study Group: Exenatide once weekly versus twice daily for the treatment of type 2 diabetes: a randomised, open-label, non-inferiority study. Lancet 2008, 372(9645):1240-1250.

26. Buse JB, Drucker DJ, Taylor KL, Kim T, Walsh B, Hu H, Wilhelm K Trautmann M, Shen LZ, Porter LE, DURATION-1 Study Group: DURATION-1: exenatide once weekly produces sustained glycemic control and weight loss over 52 weeks. Diabetes Care 2010, 33(6):1255-1261.

27. World Medical Association declaration of Helsinki: Recommendations guiding physicians in biomedical research involving human subjects. JAMA 1997, 277(11):925-926.

28. Gao Y, Yoon KH, Chuang LM, Mohan V, Ning G, Shah S, Jang HC, Wu TJ, Johns D, Northrup J, et al: Efficacy and safety of exenatide in patients of Asian descent with type 2 diabetes inadequately controlled with metformin or metformin and a sulphonylurea. Diabetes Res Clin Pract 2009, 83(1):69-76.

29. Bantle JP, Wylie-Rosett J, Albright AL, Apovian CM, Clark NG, Franz MJ, Hoogwerf BJ, Lichtenstein AH, Mayer-Davis E, Mooradian AD, et al: Nutrition recommendations and interventions for diabetes-2006: a position statement of the American Diabetes Association. Diabetes Care 2006, 29(9):2140-2157.

30. American Diabetes Association: Management of dyslipidemia in adults with diabetes. Diabetes Care 2000, 23(Suppl 1):S57-S60.

31. Buse JB, Rosenstock J, Sesti G, Schmidt WE, Montanya E, Brett JH, Zychma M, Blonde L: Liraglutide once a day versus exenatide twice a day for type 2 diabetes: a 26-week randomised, parallel-group, multinational, open-label trial (LEAD-6). Lancet 2009, 374(9683):39-47.

32. Agersø $H$, Jensen LB, Elbrønd B, Rolan P, Zdravkovic M: The pharmacokinetics, pharmacodynamics, safety and tolerability of NN2211, a new long-acting GLP-1 derivative, in healthy men. Diabetologia 2002, 45(2):195-202.

33. Aschner P, Kipnes MS, Lunceford JK, Sanchez M, Mickel C, WilliamsHerman DE: Effect of the dipeptidyl peptidase-4 inhibitor sitagliptin as monotherapy on glycemic control in patients with type 2 diabetes. Diabetes Care 2006, 29(12):2632-2637.

34. Bergenstal R, Wysham C, MacConell L, Malloy J, Walsh B, Yan P, Wilhelm K, Malone J, Porter L: Efficacy and safety of exenatide once weekly versus sitagliptin or pioglitazone as an adjunct to metformin for treatment of type 2 diabetes (DURATION-2): a randomised trial. Lancet 2010, 376(9739):431-439.

35. DeFronzo RA, Okerson T, Viswanathan P, Guan X, Holcombe JH, MacConell L: Effects of exenatide versus sitagliptin on postprandial glucose, insulin and glucagon secretion, gastric emptying, and caloric intake: a randomized, cross-over study. Curr Med Res Opin 2008, 24(10):2943-2952.

36. Best JH, Boye KS, Rubin RR, Cao D, Kim TH, Peyrot M: Improved treatment satisfaction and weight-related quality of life with exenatide once weekly or twice daily. Diabet Med 2009, 26(7):722-728.

\section{Pre-publication history}

The pre-publication history for this paper can be accessed here:

http://www.biomedcentral.com/1472-6823/11/9/prepub doi:10.1186/1472-6823-11-9

Cite this article as: Taylor et al:: Exenatide once weekly treatment maintained improvements in glycemic control and weight loss over 2 years. BMC Endocrine Disorders 2011 11:9.

\section{Submit your next manuscript to BioMed Central and take full advantage of:}

- Convenient online submission

- Thorough peer review

- No space constraints or color figure charges

- Immediate publication on acceptance

- Inclusion in PubMed, CAS, Scopus and Google Scholar

- Research which is freely available for redistribution 